\title{
Copro- Diagnosis of Early Trichinella spiralis Infection in Experimental Animals
}

\section{Dalia S Ashour*, Ibrahim A Aboul Assad, Samy I El-Kowrany and Amira E Abdel Ghaffar}

Department of Medical Parasitology, Faculty of Medicine, Tanta University, Tanta, Egypt

*Corresponding Author: Dalia S Ashour, Associate Professor, Department of Medical Parasitology, Faculty of Medicine, Tanta University, Tanta, Egypt.

Received: December 11, 2017; Published: January 30, 2018

DOI: $10.31080 /$ ASMI.2018.01.0017

\begin{abstract}
The early phase of trichinellosis is difficult to diagnose due to the non-specificity of the signs and symptoms that may be misdiagnosed as alimentary intoxication or enterobacterial infection. Therefore, it is important to study early diagnostic methods for Trichinella spiralis infection to allow medical intervention at early stages of the disease. Coproantigen has become an important alternative method for the diagnosis of intestinal infections caused by either protozoa or helminths. To investigate the sensitivity of coproantigen detection in comparison with other traditional serodiagnostics, the following techniques were performed on T. spiralis infected rats: examination of the stool for Trichinella adult or newborn larvae, detection of coproantigen by capture ELISA and PCR, ELISA for detection of Trichinella antibodies in serum and PCR for detection of Trichinella DNA in the serum. We found that Trichinella coproantigen by ELISA and PCR show positivity from $1^{\text {st }}$ day until $9^{\text {th }}$ day post infection (P.I.). PCR detected T. spiralis DNA in serum from $5^{\text {th }}$ day P.I.. Trichinella antibodies in sera detected by ELISA technique show positivity starting from $10^{\text {th }}$ day P.I. till the end of the experiment. No Trichinella adults or larvae were detected in stool. In conclusion, early diagnosis of T. spiralis showed higher sensitivity by copro-PCR and copro-ELISA followed by detection of T. spiralis DNA in serum then detection of T. spiralis antibodies in serum.

Keywords: Trichinella spiralis; Coproantigen; Copro-ELISA; Copro-PCR
\end{abstract}

\section{Introduction}

Trichinellosis is a zoonosis acquired by the ingestion of undercooked meat containing the infective larvae of Trichinella spiralis. Trichinellosis continues to be a public health concern throughout the world. It has been estimated that 11 million people worldwide could be infected [1]. Murrell and Pozio [2] reported that there is an increase in the occurrence of infection among pigs and wildlife, with a consequent increase among humans in the past 10 years. Trichinellosis is of such varied symptomatology that includes abdominal pain, diarrhea, fever, myalgia and periorbital oedema and it resembles other conditions such as nephritis, encephalitis, myositis and tetanus. Particularly, the early phase of infection is difficult to diagnose due to the non-specificity of the signs and symptoms that may be misdiagnosed as alimentary intoxication or enterobacterial infection [3].

Diagnosis of trichinellosis relies largely on the serodiagnostic procedures to detect antibodies which are of great value but unfortunately most of the diagnostic methodologies have not been able to detect the early phase of the infection when an anti-parasitic treatment would be most effective [4]. Moreover, the detection of Trichinella circulating antigens in the serum needs an extremely sensitive and stable system to detect minute quantities of circulating antigens as it fluctuates widely at various periods post infection. Therefore, it is mandatory to use; otherwise, false negative results may be easily obtained [5].
The diagnosis of intestinal infections by detection of parasitespecific antigens in faeces (coproantigens) is an approach applied to a broad range of infectious organisms [6]. This new approach has been implemented for intravital diagnostics of taeniasis and echinococcosis. The highest degree of coproantigen excretion is during the progressive growth and maturation of the adult worms with increased shedding of surface antigens that is associated with a higher metabolic rate just before patency $[7,8]$.

The main advantages of the coproantigen assay over other diagnostic methods are that coproantigens indicate the current infection only. Moreover, coproantigen excretion is closely correlated to the presence of intestinal immature and mature parasite stages and their numbers. In addition, they are detected earlier than antibodies and it does not depend on the ability of the host to develop antibody response [9].

Studies on coproantigens indicated that they are resistant to degradation by faecal enzymes, protease-insensitive and remain active after formalin treatment and even contamination by bacteria and fungi [10]. They also could be detected regardless of faecal condition; and thus coproantigen detection is useful even on faeces excreted more than 1 week previously [11].

Moreover, coproantigens are heat stable. This heat stability may be due to their highly glycosylated nature, which may also protect any protein core. Such stability is of practical importance in epide- 
miological studies. In addition, faeces could be heated before testing to render them bio-safe for handling and preventing accidental infection [12].

An important recent advance has been the development of copro polymerase chain reaction (copro-PCR) by amplification of parasite derived DNA from faeces with reportedly high sensitivity and specificity $[13,14]$. In recent years, a new diagnostic approach based on the detection of parasite DNA by PCR have been developed for early diagnosis of hook worms [15] and filariasis [16].

Therefore, this work aimed to investigate coproantigens detection as a possible diagnostic tool for early diagnosis of T. spiralis infection in experimental animals in comparison to other traditional serodiagnostics.

\section{Materials and Methods}

\section{Ethics statement}

Animals used in this study were housed and maintained in accordance with the institutional and national guidelines. The experimental study was carried out in Medical Parasitology department, Faculty of Medicine, Tanta University. All animal procedures reported herein were reviewed and approved by the Research Ethics Committee, Quality Assurance Unit, Faculty of Medicine, Tanta University.

\section{Animals and experimental design}

A total of 110 male Swiss albino rats, 6 - 8 weeks old, weighing 150 - 200 gram each were used. One hundred rats were experimentally infected with $T$. spiralis while ten rats remained uninfected as a control group. Each time, five infected rats were isolated where their faeces were collected then, these rats were sacrificed and the blood was collected from the vena cava in a clean, dry tube then serum was collected into small plastic eppendorfs. The samples were stored at $-20^{\circ} \mathrm{C}$ until used. Specimens' collection from rats was performed daily from the first day up to the $10^{\text {th }}$ day post infection (P.I.) then every other day until the end of the experiment. Then the following techniques were performed: parasitological examination of the stool and detection of coproantigen by ELISA and PCR; detection of T. spiralis DNA in the serum by PCR and detection of T. spiralis antibodies in the serum by ELISA technique.

\section{Trichinella spiralis infection}

Rats were infected with Trichinella spiralis larvae in a dose of 1000 larvae orally according to Dunn and Wright [17]. The strain of Trichinella spiralis was isolated from infected pork meat obtained from Cairo abattoir and maintained in the laboratory of Medical Parasitology department, Tanta Faculty of Medicine by consecutive passages through rats and mice.

\section{Parasitological examination of the stool}

A wet mount preparation technique was performed to identify larvae or adults of T. spiralis [18]. Systematically, the entire cover area was scanned using the $10 \times$ objective lens.

\section{Preparation of faecal extracts}

Stool samples were weighed and thoroughly homogenized with 3 volumes of cold phosphate-buffered saline (PBS) plus $0.05 \%$ Tween-20. Each sample was then shaken vigorously to form homogenates and centrifuged for 15 minutes at $1200 \mathrm{rpm}$ at $4^{\circ} \mathrm{C}$. Supernatants were collected and kept at $-20^{\circ} \mathrm{C}$. until used for T. spiralis coproantigen detection by both ELISA and PCR [19].

Detection of T. spiralis coproantigen by capture Enzyme linked immunosorbent assay (Capture ELISA)

Capture ELISA was used for the determination of Trichinella coproantigen using T. spiralis Antigen Detection- Microwell ELISA (Immuno-Biological Laboratories, Inc., USA). It is a sandwich ELISA using anti- Trichinella polyclonal antibodies to capture the antigen present in the stool supernatant. A second anti-rat IgG- goat antibody peroxidase conjugate diluted 1: 1000 is then added which sandwiches the captured antigen. The reaction is visualized by the addition of the chromogen tetramethylbenzidine (TMB), which develops a blue color in the presence of the enzyme complex and peroxide. The stop solution is added which changes the blue to a yellow endpoint color. The absorbance of the specimen was measured at $450 \mathrm{~nm}$ within 30 minutes after addition of the stop solution. The negative reaction is colorless and indicates that none or undetectable level of Trichinella antigen is present in the sample tested. The positive reaction develops yellow color of variable intensity. Absorbance reading of 0.12 optical density (OD) units and above indicates positive samples $[4,20]$.

Detection of Trichinella spiralis DNA in stool by copro polymerase chain reaction (copro PCR)

PCR is based on amplification of DNA fragment then detection of nucleotide sequence typical to T. spiralis. The following steps were done.

\section{DNA extraction}

DNA extraction was done according to Ausubel., et al. [21] using DNA extraction kit; QIAamp ${ }^{\circledR}$ DNA Mini Kit (QIAGEN, Germany). Stool samples typically contain many compounds that can degrade DNA and inhibit enzymatic reactions. The QIAamp DNA Mini Kit removes these substances through the action of a reagent that efficiently adsorbs inhibitors. Then allow proper storage of the extracted DNA at $-20^{\circ} \mathrm{C}$.

\section{PCR amplification protocol}

PCR Master Mix kit (Promega, USA) was used for PCR reaction. The kit included $1.25 \mathrm{ml}$ Nuclease-Free Water and $1.25 \mathrm{ml}$ PCR Master Mix. PCR Master Mix is a premixed, ready-to-use solution containing 50 units $/ \mathrm{ml}$ of Taq DNA polymerase supplied in a reaction buffer (pH 8.5), $400 \mu \mathrm{M}$ dATP (Deoxyadenosine triphosphate), $400 \mu \mathrm{M}$ dGTP (Deoxyguanosine triphosphate), $400 \mu \mathrm{M}$ dCTP (Deoxycytosine triphosphate), $400 \mu \mathrm{M}$ dTTP (Deoxythymidine triphosphate), $3 \mathrm{mM} \mathrm{MgCl}$ and reaction buffers at optimal concentrations for efficient amplification of DNA templates by PCR. The two primers used were PRA200 (5'- CTTGTAAAGC GGTGGTGCGTA -3') and PRA800 (5'- AGGTAATGTTTGCCTCTCTATG- 3'), which were derived from Trichinella spiralis 1.6- $\mathrm{kb}$ repetitive DNA sequence [22]. The specific primers were supplied by Sigma (UK) as lyophilized powder to be reconstituted upon use. Each primer was dissolved in $100 \mu$ l. sterile nuclease free water (Promega, USA). PCR was performed according to the method described by Stensvold., et al. [23] and Duenngai., et al [24]. The amplified products were analysed by electrophoresis in $2 \%$ agarose gels (Hispangr, Burges, Spain) and detected by staining with ethidium bromide in concentration $10 \mathrm{mg} / \mathrm{ml}$ (Amersco, USA).

Detection of Trichinella spiralis antibodies in serum by ELISA assays

ELISA technique was used for qualitative detection of antibodies using T. spiralis Anti-rat IgG ELISA (Immuno-Biological Laboratories, Inc. USA) in which microtiter plate wells were coated with T. spiralis excretory/secretory (E/S) antigens partially purified in conditions capable of maintaining the antigens' native form. Diluted control and test sera are distributed in the wells, allowing any T. spiralis antibodies that are present to bind to the adsorbed antigen. After washing the wells to remove all unbound sample material, horseradish peroxidase (HRP) conjugated anti-rat IgG antibodies at a $1 / 10.000$ dilution is then added to each well. This conjugate binds to the captured T. spiralis specific antibodies. The immune complex formed by the bound conjugate is visualized by adding Tetramethylbenzidine (TMB) substrate as color change. Absorbance at $450 \mathrm{~nm}$ is read using an ELISA microwell plate reader. Absorbance reading of 0.12 OD units and above indicates positive samples [25-27]. 


\section{Detection of T. spiralis DNA in serum}

The technique used for detection of T. spiralis DNA in serum is the same as that used for detection of T. spiralis DNA in stool [28].

\section{Statistical analysis}

Quantitative data regarding mean \pm standard deviation (SD) were analyzed by ANOVA using the software package Graphpad Instat version 3. P values lower than 0.05 were considered statistically significant.

\section{Results}

Parasitological examination of the stool

No T. spiralis larvae or adults were detected in the stool of all rats examined all over the experimental period.

\section{Detection of $T$. spiralis coproantigen in stool of rats using capture ELISA technique}

The optical density values as compared to that of the control group were presented in table 1 . The cut- off value was 0.12 . The mean optical density values showed positivity from the $1^{\text {st }}$ day P.I. and reached their peak on the $5^{\text {th }}$ and $6^{\text {th }}$ days P.I.. The sensitivity of ELISA technique in measuring coproantigen level ranged from $60 \%$ to $80 \%$ in the first 3 days post infection, then achieved $100 \%$ sensitivity from $4^{\text {th }}$ day to $9^{\text {th }}$ day post infection. The sensitivity decreased from $10^{\text {th }}$ day till the end of the experiment. Control group showed negative results. It also showed that the mean optical densities of T. spiralis coproantigen of rats using ELISA technique in the middle and last 10-days of the experimental period were significantly lower than those in the first 10 days.

\begin{tabular}{|c|c|c|c|c|c|c|c|c|c|c|c|c|c|c|c|c|c|c|c|c|}
\hline $\begin{array}{l}\text { Days post } \\
\text { infection }\end{array}$ & 1 & 2 & 3 & 4 & 5 & 6 & 7 & 8 & 9 & 10 & 12 & 14 & 16 & 18 & 20 & 22 & 24 & 26 & 28 & 30 \\
\hline Mean OD & 0.16 & 0.21 & 0.32 & 0.53 & 0.92 & 0.95 & 0.82 & 0.47 & 0.42 & 0.11 & 0.11 & 0.11 & 0.1 & 0.1 & 0.09 & 0.06 & 0.06 & 0.06 & 0.05 & 0.05 \\
\hline S.D. & 0.078 & 0.064 & 0.028 & 0.033 & 0.041 & 0.029 & 0.033 & 0.048 & 0.03 & 0.017 & 0.019 & 0.022 & 0.021 & 0.026 & 0.018 & 0.027 & 0.019 & 0.016 & 0.006 & 0.013 \\
\hline $\begin{array}{l}\text { Minimum } \\
\text { OD }\end{array}$ & 0.09 & 0.10 & 0.29 & 0.47 & 0.87 & 0.91 & 0.77 & 0.40 & 0.37 & 0.08 & 0.08 & 0.08 & 0.07 & 0.05 & 0.06 & 0.04 & 0.04 & 0.04 & 0.04 & 0.04 \\
\hline $\begin{array}{l}\text { Maximum } \\
\text { OD }\end{array}$ & 0.27 & 0.29 & 0.38 & 0.58 & 0.99 & 0.99 & 0.87 & 0.50 & 0.47 & 0.14 & 0.14 & 0.15 & 0.14 & 0.15 & 0.12 & 0.12 & 0.09 & 0.09 & 0.06 & 0.08 \\
\hline Sensitivity & $40 \%$ & $80 \%$ & $100 \%$ & $100 \%$ & $100 \%$ & $100 \%$ & $100 \%$ & $100 \%$ & $100 \%$ & $40 \%$ & $30 \%$ & $30 \%$ & $30 \%$ & $20 \%$ & $10 \%$ & $10 \%$ & $0 \%$ & $0 \%$ & $0 \%$ & $0 \%$ \\
\hline$P$ value & & & & & & & & & & & $\begin{array}{c}< \\
0.05^{*}\end{array}$ & & & & & $\begin{array}{c}< \\
0.01^{*}\end{array}$ & & & & \\
\hline
\end{tabular}

Table 1: The mean optical densities of T. spiralis coproantigen using ELISA technique in rats experimentally infected with T. spiralis. * Significant

\section{Detection of $T$. spiralis coproantigen in stool of rats by copro PCR}

It was found that stool samples of rats infected with T. spiralis were positive for PCR detection of T. spiralis DNA giving positive bands at $425 \mathrm{bp}$ from the $1^{\text {st }}$ day post infection and onward till $9^{\text {th }}$ day post infection (Figure 1 and 2). So, examination of stool samples showed the same results by using both PCR for detection of T. spiralis DNA and ELISA for detection of Trichinella coproantigen (Positive from $1^{\text {st }}$ day till $9^{\text {th }}$ day P.I.).

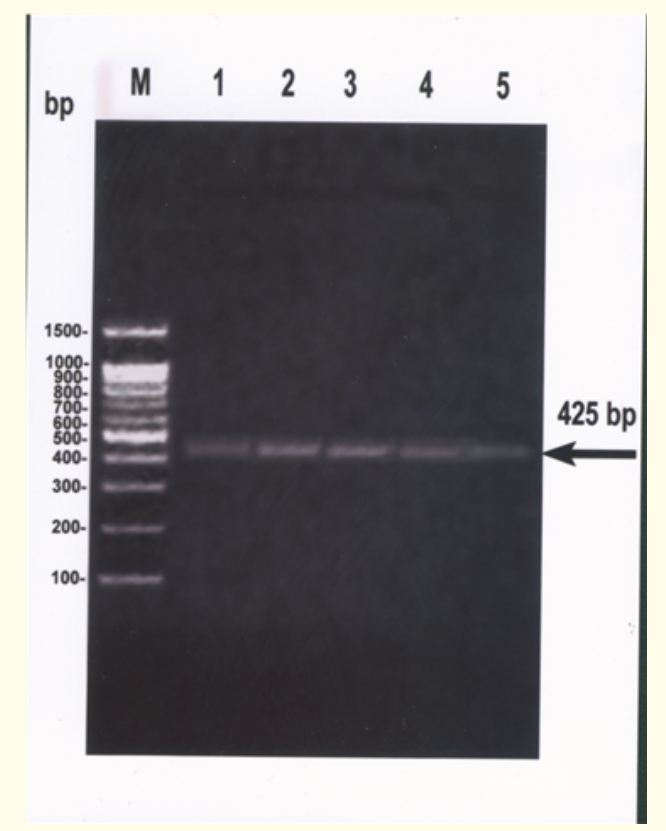

Figure 1: Electrophoretic patterns of an ethidium bromide-stained $2 \%$ agarose gel under UV light illumination showing PCR products of T. spiralis DNA from stool samples of infected rats. M: marker ladder. Lanes 1 - 5 represent positive bands at 425 bp on days 1 - 5 P.I.

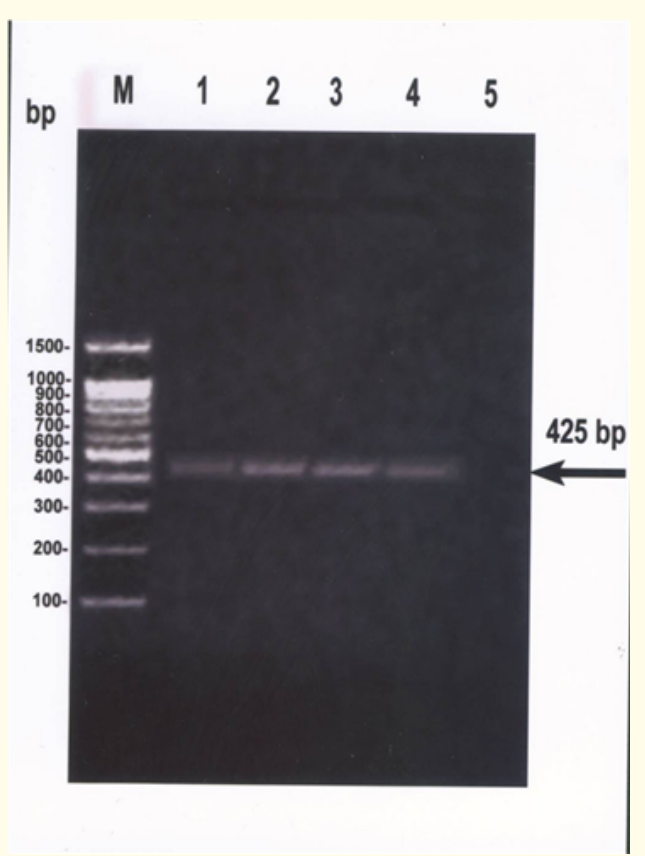

Figure 2: Electrophoretic patterns of an ethidium bromide-stained 2\% agarose gel under UV light illumination showing PCR products of T. spiralis DNA from stool samples of infected rats. M: marker ladder. Lanes 1 - 4 represent positive bands at

425 bp on days 6 - 9 P.I.. Lane 5 represent negative sample on 10th day P.I.

\section{Detection of $T$. spiralis DNA in sera of infected rats by PCR}

It was found that serum samples of rats infected with T. spiralis were positive for PCR detection of T. spiralis DNA giving positive bands at $425 \mathrm{bp}$ from 5 th day post infection and onward till the end of the experiment (Figure 3 and 4). 


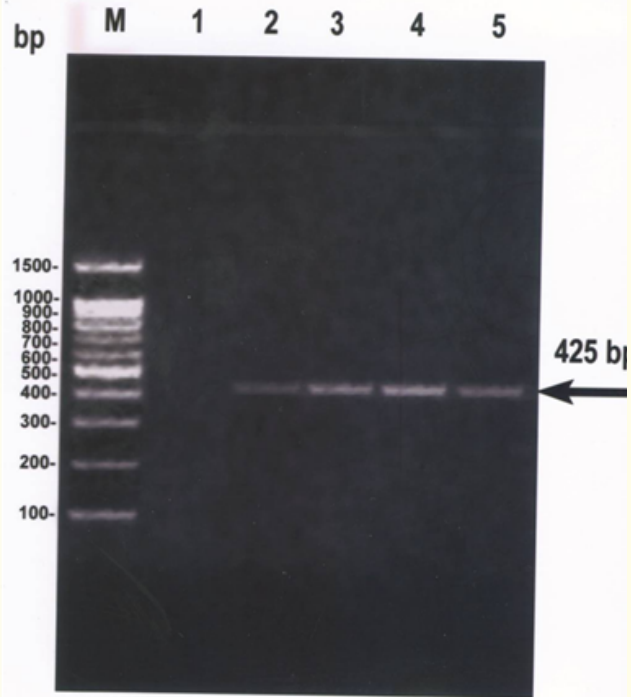

Figure 3: Electrophoretic patterns of an ethidium bromide-stained 2\% agarose gel under UV light illumination showing PCR products of T. spiralis DNA from serum samples of infected rats. M: marker ladder. Lane 1 represents negative sample on day 4 P.I. Lanes 2 - 5 represent positive bands at 425 bp on days 5 - 8 P.I.

Detection of T. spiralis antibodies in sera of infected rats using ELISA technique

The optical density values as compared to that of the control group were shown in table 2 . The cut- off value was 0.12 . The mean optical density values showed positivity starting from 10th day post infection till the end of the experiment. The sensitivity of the test was low in the first five days ranging from $10 \%$ to $30 \%$ then it increased from $50 \%$

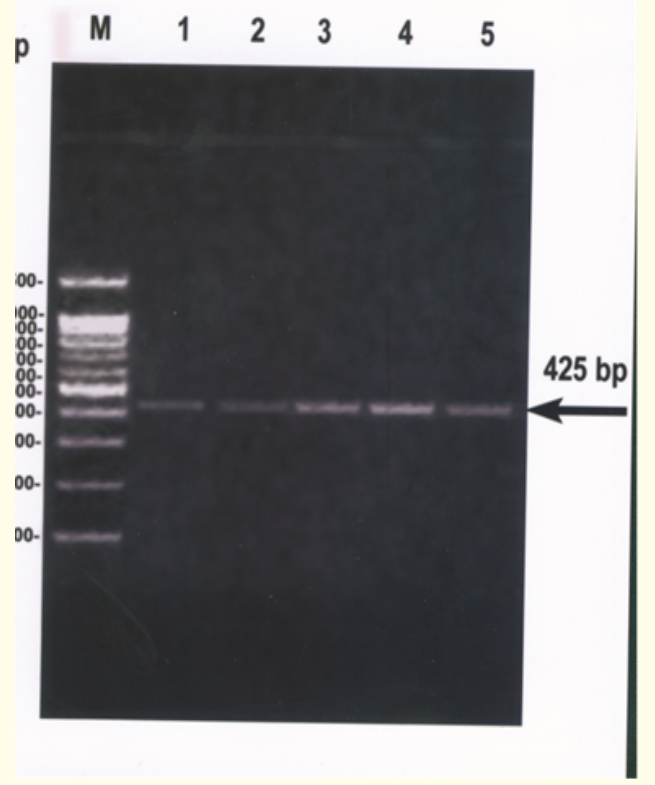

Figure 4: Electrophoretic patterns of an ethidium bromide-stained $2 \%$ agarose gel under UV light illumination showing PCR products of T. spiralis DNA from serum samples of infected rats. M: marker ladder. Lanes 1 - 5 represent positive bands at 425 bp on days 9 - 13 P.I.

\begin{tabular}{|c|c|c|c|c|c|c|c|c|c|c|c|c|c|c|c|c|c|c|c|c|}
\hline $\begin{array}{l}\text { Days post } \\
\text { infection }\end{array}$ & 1 & 2 & 3 & 4 & 5 & 6 & 7 & 8 & 9 & 10 & 12 & 14 & 16 & 18 & 20 & 22 & 24 & 26 & 28 & 30 \\
\hline Mean OD & 0.06 & 0.06 & 0.09 & 0.09 & 0.10 & 0.11 & 0.11 & 0.11 & 0.11 & 0.12 & 0.28 & 0.39 & 0.35 & 0.33 & 0.41 & 0.42 & 0.45 & 0.48 & 0.42 & 0.51 \\
\hline S.D. & 0.019 & 0.027 & 0.018 & 0.029 & 0.028 & 0.026 & 0.025 & 0.019 & 0.030 & 0.026 & 0.029 & 0.043 & 0.029 & 0.023 & 0.023 & 0.04 & 0.023 & 0.037 & 0.028 & 0.04 \\
\hline $\begin{array}{l}\text { Minimum } \\
\text { OD }\end{array}$ & 0.04 & 0.04 & 0.06 & 0.05 & 0.06 & 0.05 & 0.07 & 0.08 & 0.06 & 0.06 & 0.22 & 0.32 & 0.29 & 0.30 & 0.38 & 0.36 & 0.42 & 0.40 & 0.35 & 0.45 \\
\hline $\begin{array}{l}\text { Maximum } \\
\text { OD }\end{array}$ & 0.09 & 0.12 & 0.12 & 0.15 & 0.15 & 0.14 & 0.15 & 0.14 & 0.15 & 0.14 & 0.32 & 0.44 & 0.39 & 0.37 & 0.45 & 0.46 & 0.49 & 0.55 & 0.45 & 0.56 \\
\hline Sensitivity & $0 \%$ & $10 \%$ & $10 \%$ & $20 \%$ & $30 \%$ & $50 \%$ & $50 \%$ & $50 \%$ & $70 \%$ & $80 \%$ & $100 \%$ & $100 \%$ & $100 \%$ & $100 \%$ & $100 \%$ & $100 \%$ & $100 \%$ & $100 \%$ & $100 \%$ & $100 \%$ \\
\hline P value & & & & & & & & & & & $\begin{array}{c}< \\
0.001^{* *}\end{array}$ & & & & & $\begin{array}{c}< \\
0.001^{* *}\end{array}$ & & & & \\
\hline
\end{tabular}

Table 2: The mean optical densities of T. spiralis antibodies in sera using ELISA technique in rats experimentally infected with T. spiralis. ** Highly significant

\section{Discussion}

Diagnosis of T. spiralis infection relies largely on antibody detection by serodiagnostic procedures that are of great value, but unfortunately their maximal positive rates were not reached until at least 3 - 4 weeks P.I. and the persistence of antibodies for long periods limits the suitability of these tests [29]. Thus, up till now, there is no accurate method to diagnose trichinellosis at the early stages of infection. This drawback may limit medical intervention at early stages of disease [4]. The present work was designed to study sensitive diagnostic methods for early detection of T. spiralis infection by tracking the existence of T. spiralis antigen in stool and serum of infected rats in comparison to the onset of antibodies formation in serum. to $80 \%$ from $5^{\text {th }}$ day to $10^{\text {th }}$ day post infection. While it achieved $100 \%$ sensitivity from $12^{\text {th }}$ day post infection till the end of the experiment. Control group showed negative results. The mean optical densities of $T$. spiralis antibodies in sera of rats using ELISA technique in the middle and last 10 days of the experimental period were significantly higher than those of the first 10 days.
In this work, parasitological examination of the stool revealed no T. spiralis larvae or adults in the stool of all rats examined all over the experimental period. Näreaho [30] stated that adult worms or larvae are difficult to be detected in the stool because they tend to be degenerated.

Concerning T. spiralis coproantigen, it could be detected in the present study in infected rats using capture ELISA technique starting from the first day P.I. then increased gradually to reach its peak on the $5^{\text {th }}$ and $6^{\text {th }}$ days P.I.. No antigen was detected in the stool during the $3^{\text {rd }}$ and $4^{\text {th }}$ weeks P.I. probably because at this stage all worms have already been expelled and the larvae have already reached the tissues. These results were confirmed by Boulos., et al. [4] who suggested that the detected antigen could 
be associated with the turnover of the parasite surface, degenerated larvae or adults expelled in the stool or it may be excretory/ secretory product of the parasite. However, Nuñez and Venturiello [31] and Nuñez., et al. [19] determined the presence of parasite antigen in faecal extracts using ELISA technique and were able to detect considerable levels of antigen only on the second day P.I.. The negative results after the $9^{\text {th }}$ day P.I. in the present experiment can be explained in many ways: first, it is possible that the amount of antigen released by the parasite is too low to be detected; second, it is probable that negative results are due to immune complex formation between coproantigens and coproantibodies and third, the loss of some E/S products may be inevitable in faeces may because of a variety of microorganisms and active enzymes from the gut, that might damage the specific epitopes involved in the detection of Trichinella antigens by the assay $[32,33]$.

Bungiro and Cappello [7] demonstrated the ability of the capture ELISA to detect hookworm coproantigens early in the prepatent period and in low intensity infections that might not be detected by conventional microscopy, allowing for more accurate estimates of hookworm prevalence. Coproantigen ELISAs have also been reported to be a sensitive, specific and rapid procedure for the detection of other parasites such as Strongyloides ratti [34] in rats, Fasciola hepatica in infected animals [35], Echinostoma caproni [36] and Teladorsagia circumcincta [33] in sheep.

In the present study, it was found that PCR of stool samples of infected rats were positive for T. spiralis DNA from the first day post infection and onward till the $9^{\text {th }}$ day post infection after which it became negative till the end of the experiment. The failure of coproantigen detection in the late samples could be explained by the low concentration of coproantigens. The high metabolic activities during the early fast growing phase of the worms might be responsible for the high concentrations of coproantigens $[37,38]$.

Deplazes., et al. [38] stated that PCR-based diagnosis of intestinal infections has to be implemented within a diagnostic strategy while Eckert and Deplazes [39] suggested the use of copro-ELISA as a primary screening test, and copro-PCR as a secondary confirmatory test. Deplazes., et al. [38] stated that although PCR technique is sensitive enough to detect parasite-specific DNA from a very small amount of the parasite, it is not suitable for large scale screening of samples; an important consideration in the design of control and surveillance systems. Thus, PCR based techniques are well suited as confirmatory tools [40]. Deplazes., et al. [41] stated that coproantigen stability is a prerequisite for the usefulness of its detection not only in fresh but also in weathered samples from the environment. It has been documented that helminth coproantigens could be stable for at least 5 days at room temperature [12]

Mathis and Deplazes [14] reported that copro-DNA detection by PCR have been successfully developed and evaluated for the diagnosis of Taenia. Diagnosis during the prepatent period is one of the advantages of coproantigen detection assays because, at this stage, diagnosis is impossible by a standard faecal egg examination method. Copro-PCR was also assessed for prepatent infection of Echinococcus granulosus and it was sensitive to detect low pre-patent worm burden to the degree that it has the ability to amplify nonegg associated DNA of E. granulosus [13]. Moreover, coproantigen detection assay could be performed safely with samples containing infective parasite eggs as in the diagnosis of E. multilocularis during the patent period in the definitive host. Therefore, a heat-resistant coproantigen detection assay has been developed because the eggs of E. multilocularis lose infectivity after incubation at $44^{\circ} \mathrm{C}$ for $12 \mathrm{~h}$ [9]. Johnson., et al. [33] stated that this heat-based treatment of faecal supernatant is beneficial in reducing the possible cross-reactivity between T. spiralis and other gastrointestinal nematodes.
Espino., et al. [42] stated that coproantigens of $F$. hepatica are detectable several weeks before egg excretion and before detection of circulating antigens. Regarding trichinellosis, coproantigen detection is a simple method that can be helpful during the intestinal phase, in surveys and also in Trichinella outbreaks. Also, coproantigens rapidly disappear from faeces after treatment, so it is a good marker of active infection and for follow up of effectiveness of treatment [4].

In the present study, it was found that PCR of serum samples of infected rats were positive for T. spiralis DNA from the 5th day post infection and onward till the end of the experiment. T. spiralis DNA detection has often been related to the presence of the migratory larvae in the blood and the presence of larvae in close contact with the tissues of the host [36]. Many studies on the detection of antigens shed by T. spiralis migratory larvae into the blood have been reported $[28,43,44]$. They showed that PCR could detect the presence of migratory larvae in blood from $5^{\text {th }}$ day up to at least $14^{\text {th }}$ day post infection while Caballero- Garcia and Jimenez- Cardoso [45] could detect migratory larvae in blood from $5^{\text {th }}$ day up to $17^{\text {th }}$ day post infection. Furthermore Perret., et al. [46] assess the presence of new born larvae by the polymerase chain reaction. $T$. spiralis DNA was detected from the $6^{\text {th }}$ to the $14^{\text {th }}$ day post infection. They explained the presence of T. spiralis DNA from $6^{\text {th }}$ day P.I. by the presence of migratory larvae or their products in the blood stream from the onset of production of newborn larvae until the expulsion of adult worms. These results are consistent with the biology and life cycle of $T$. spiralis, in which life span of adult in rats is 10 - 20 days. In addition, Trichinella females are the most fecund during the first week of larval production [19]

While the discrepancies between the last day of T. spiralis DNA detection in our experiment and other studies are likely due to the efficiency of extraction from the blood samples with low numbers of migratory larvae as occurred in the latter samples, which did not give consistently positive results. Therefore, the ability to detect circulating larvae by PCR depends on both the density of larvae in the bloodstream and on the amount of blood used for DNA extraction [28,45]. Arriaga., et al. [44] demonstrated that an increase in circulating antigen was followed by an increase in antibody levels with the subsequent decrease in free antigen. Similar results were obtained in rat trichinellosis by Todorova., et al [47]. This could be explained by the formation of immune complexes which in turn are eliminated by the host, as has been reported to occur in human trichinellosis.

In the present study, detection of T. spiralis antibodies in sera of rats using excretory/secretory $(\mathrm{E} / \mathrm{S})$ antigen by ELISA technique, started from the $10^{\text {th }}$ day P.I. till the end of the present experiment. These results are in agreement with those reported by Nunez., et al [19]. They showed that serum T. spiralis antibodies were detected from $10^{\text {th }}$ day P.I. onwards. Also, Perret., et al. [46] stated that the early antibodies were detected on $11^{\text {th }}$ day P.I. and decreased from $48^{\text {th }}$ day P.I.. However, earlier results were described by Näreaho [30] who detected the first sign of seroconversion as early as one week post infection then the levels of Trichinella antibodies increased rapidly during the first three weeks of infection. Others described late T. spiralis antibodies seroconversion to positive approximately of 3 weeks P.I. [48]. While Murrell., et al. [49] observed late seroconversion varying between 5 and 18 weeks P.I. in Trichinella infected horses. This discrepancy could be explained by Serrano., et al. [50] who reported that the antibody response against $T$. spiralis showed a significant relation with the infecting dose and intensity of infection or it may be due to the use of different hosts. 
In experimental murine trichinellosis, Kolodziej-Sobocińska., et al. [51] stated that T. spiralis specific antibodies lasted for 7 months P.I.. In human trichinellosis, the persistence of antibodies has been demonstrated for as long as one year [43,52] and even up to three years post infection [53]. The possible explanation is that the antibody response to T. spiralis is known to be elicited by the muscle larvae and Trichinella antigen can enter the peripheral circulation directly via the circulatory rete on the surface of the nurse cell. The consistent release of circulating antigens by the larvae as well as degradation of larvae by inflammatory cells may play a major role in sustaining the long-lasting antibody response until calcification of the parasites [54-56].

\section{Conclusion}

In conclusion, our results clearly showed the sensitivity of detection of Trichinella coproantigens (which is more sensitive using PCR than ELISA) that can be implemented in early diagnosis or during the prepatent period. Together with its easy safe manipulation, this assay could be an ultimate tool for understanding the epidemiology of many parasites and for assessment of subsequent control measures. Moreover, the assay could serve as a useful tool for monitoring parasite development and changes in parasite burden during an experimental infection, leading to further understanding of the parasite's biology and the host-parasite relationship.

\section{Bibliography}

1. Crompton DWT and Savioli L. "Trichinellosis". In: Handbook of Helminthiasis for Public Health. By: Taylor and Francis Group LLC (2007): 261-272

2. Murrell KD and Pozio E. “Trichinellosis: the zoonosis that won't go quietly". International Journal for Parasitology 30.12-13 (2000): 1339-1349.

3. Al-Sherbiny MM., et al. "Application and assessment of a dipstick assay in the diagnosis of hydatidosis and trichinosis". Parasitology Research 93.2 (2004): 87-95.

4. Boulos LM., et al. "Detection of coproantigen in early trichinellosis”. Parasite 8.2 (2001): S136-S139.

5. Li CK and Ko RC. "The detection and occurrence of circulating antigens of Trichinella spiralis during worm development". Parasitology Research 87.2 (2001): 155-162.

6. Allan JC and Craig PS. "Coproantigens in taeniasis and echinococcosis”. Parasitology International 55.1 (2006): S75-S80.

7. Bungiro RD and Cappello M. "Detection of excretory/secretory coproantigens in experimental hookworm infection". American Journal of Tropical Medicine and Hygiene 73.5 (2005): 915-920.

8. Al-Sabi MN., et al. "Comparative copro-diagnosis of Echinococcus multilocularis in experimentally infected foxes". Parasitology Research 101.3 (2007): 731-736.

9. Eckert J. "Predictive values and quality control of techniques for the diagnosis of Echinococcus multilocularis in definitive hosts". Acta Tropica 85.2 (2003): 157-163.

10. Elayoubi FA and Craig PS. "Echinococcus granulosus coproantigens: chromatographic fractionation and characterization". Parasitology 128.4 (2004): 455-465.

11. Machnicka B., et al. "Detection of Echinococcus multilocularis antigens in faeces by ELISA". Parasitology Research 91.6 (2003): 491-496.

12. Jenkins DJ., et al. "Detection of Echinococcus granulosus coproantigens in Australian canids with natural or experimental infection". Journal of Parasitology 86.1 (2000): 140-145.

13. Abbasi I., et al. "Copro-diagnosis of Echinococcus granulosus infection in dogs by amplification of a newly identified repeated DNA sequence". American Journal of Tropical Medicine and Hygiene 69.3 (2003): 324-330.
14. Mathis A and Deplazes P. "Copro-DNA tests for diagnosis of animal taeniid cestodes". Parasitology International 55.1 (2006): S87-S90.

15. De Gruijter JM., et al. "Polymerase chain reaction-based differential diagnosis of Ancylostoma duodenale and Necator americanus infections in humans in northern Ghana". Tropical Medicine and International Health 10.6 (2005): 574-580.

16. Hassan M., et al. "Detection of DNA of W. bancrofti in blood samples by QC-PCR-ELISA-based". Journal of the Egyptian Society of Parasitology 35.3 (2005): 963-970.

17. Dunn IJ and Wright KA. "Cell injury caused by Trichinella spiralis in the mucosal epithelium of B10A mice". Journal of Parasitology 71.6 (1985): 757-766.

18. Peruzzi S., et al. "Prevalence of intestinal parasites in the area of Parma during the year 2005". Acta Biomedica 77.3 (2006): 147-151.

19. Nunez GG., et al. "Immunoparasitological parameters of the intestinal phase of trichinellosis in rats". Parasitology 126.4 (2003): 321-325.

20. Duménigo BE., et al. "Kinetics of antibody-based antigen detection in serum and faeces of sheep experimentally infected with Fasciola hepatica". Veterinary Parasitology 89.1-2 (2000): 153-161.

21. Ausubel MF., et al. "Short protocols in molecular biology". $5^{\text {th }}$ edition, volume 1. By: John Wiley and Sons, Inc., NY (2002): $67-70$

22. De Vos T., et al. "Sequence analysis of a $1.6 \mathrm{~kb}$ repetitive element from porcine isolate of Trichinella spiralis". Nucleic Acids Research 16.7 (1988): 3114- 3115.

23. Stensvold CR., et al. "Evaluation of PCR based coprodiagnosis of human opisthorchiasis". Acta Tropica 97.1 (2006): 26-30.

24. Duenngai K., et al. "Improvement of PCR for detection of Opisthorchis viverrini DNA in human stool samples". Journal of Clinical Microbiology 46.1 (2008): 366-368.

25. Gamble HR., et al. "Diagnosis of swine trichinellosis by enzyme-linked immunosorbent assay (ELISA) using an excretory-secretory antigen". Veterinary Parasitology 13.4 (1983): 349-361.

26. Salinas-Tobon MR., et al. "Class and subclass specific antibody responses to TSL-1 antigens during Trichinella spiralis human infection". In: Ortega-Pierres G, Gamble R, Van Knapen F, Wakelin D (Editors), Proceedings of the $9^{\text {th }}$ International Conference on Trichinellosis, México (1997): 453-462.

27. Nöckler K., et al. "Detection of Trichinella infection in food animals". Veterinary Parasitology 93.3-4 (2000): 335-350.

28. Upranukraw $\mathrm{P}$ and Morakote N. "Detection of circulating Trichinella spiralis larvae by polymerase chain reaction". Parasitology Research 83.1 (1997): 52-56.

29. Sánchez-Andrade R., et al. "Use of a sandwich-enzyme-linked immunosorbent assay (SEA) for the diagnosis of natural Fas ciola hepatica infection in cattle from Galicia (NW Spain)". Veterinary Parasitology 93.1 (2000): 39-46.

30. Näreaho A. "Experimental and immunological comparison of Trichinella spiralis and Trichinella nativa". Ph. D. Thesis, Department of Basic Veterinary Sciences Faculty of Veterinary Medicine, University of Helsinki, Finland (2006): 41- 43.

31. Nuñez GG and Venturiello SM. "Early detection of the intestinal phase of murine trichinellosis". In: Proceedings of the Tenth International Conference on Trichinellosis. Fontainebleau, France. Parasite 8.2 (2001): S171-175.

32. Hanvanich M., et al. "Stool desorbing activity: a possible cause of false positive reactions in competitive enzyme immunoassays". Journal of Clinical Microbiology 21.2 (1985): 184-188. 
33. Johnson DA., et al. "Copro-antigen capture ELISA for the detection of Teladorsagia (Ostertagia) circumcincta in sheep: improvement of specificity by heat treatment". Parasitology 129.1 (2004): 115-126.

34. Nageswaran C., et al. "Coproantigen detection in rats experimentally infected with Strongyloides ratti". Parasitology 108.3 (1994): 335-342.

35. Paz-Silva A., et al. "Time-course analysis of coproantigens in rats infected and challenged with Fasciola hepatica". Parasitology Research 88.6 (2002): 568-573.

36. Toledo R., et al. "Kinetics of Echinostoma caproni (Trematoda: Echinostomatidae) antigens in faeces and serum of experimentally infected hamsters and rats". Journal of Parasitology 90.4 (2004): 752-758.

37. Deplazes P., et al. "Echinococcus multilocularis coproantigen detection by enzyme-linked immunosorbent assay in fox, dog, and cat populations". Journal of Parasitology 85.1 (1999): 115121.

38. Deplazes P., et al. "Molecular tools for studies on the transmission biology of Echinococcus multilocularis". Parasitology 127 (2003): S53-S61.

39. Eckert J and Deplazes P. "Immunological and molecular techniques for diagnosing the Echinococcus multilocularis infection in definitive and intermediate hosts". Acta Parasitologica 46.1 (2001): 1-7.

40. Torgerson PR and Budke CM. "Echinococcosis -an international public health challenge". Research in Veterinary Science 74 (2003): 191-202.

41. Deplazes P., et al. "Detection of Taenia hydatigena copro-antigens by ELISA in dogs". Veterinary Parasitology 36.1-2 (1990): 91-103.

42. Espino AM., et al. "Dynamics of antigenemia and coproantigens during a human Fasciola hepatica outbreak". Journal of Clinical Microbiology 36.9 (1998): 2723-2726.

43. Machnicka B., et al. "Antibodies, circulating immune complexes in human trichinosis". In: Trichinellosis, Proceedings of the Eighth International Conference on Trichinellosis. Istituto Superiore di Sanita Press, Rome (1994): 341-346.

44. Arriaga C., et al. "Detection of circulating Trichinella spiralis muscle larva antigens in serum samples of experimentally and naturally infected swine". Veterinary Parasitology 58.4 (1995): 319-326.

45. Caballero-Garcia ML and Jimenez-Cardoso E. "Early detection of Trichinella spiralis infection by the polymerase chain reaction in blood samples of experimentally infected mice". Parasite 8.2 (2001): S229-S231.

46. Perret C., et al. "Circulating new born larvae are an early marker of Trichinella spiralis horse infection". Parasitology International 47 (1998): 283-389.

47. Todorova VK., et al. "Trichinella spiralis characterization of circulating and immune-complex-associated antigens". Parasitology Research 79.1 (1993): 86-88

48. Moller LN., et al. "Comparison of two antigens for demonstration of Trichinella spp. antibodies in blood and muscle fluid of foxes, pigs and wild boars". Veterinary Parasitology 132.1-2 (2005): 81-84.

49. Murrell KD., et al. "Epidemiology of Trichinella infection in the horse: the risk from animal product feeding practices". Veterinary Parasitology 123.3-4 (2004): 223-233.

50. Serrano FJ., et al. "Comparison of IgG, IgG1 and IgG2 responses to Trichinella spiralis and Trichinella britovi in swine". Parasite 8.2 (2001): S133-S135.

51. Kolodziej-Sobocińska M., et al. "Trichinella spiralis: Macrophage activity and antibody response in chronic murine infection". Experimental Parasitology 112.1 (2006): 52-62.

52. Bruschi F., et al. "Parasite-specific antibody response in Trichinella sp. 3 human infection: a one year follow-up". American Journal of Tropical Medicine and Hygiene 43.2 (1992): 186193.

53. Morales MAG., et al. "Increased CD8+-T-cell expression and a type 2 cytokine pattern during the muscular phase of Trichinella infection in humans". Infection and Immunity 70.1 (2002): 233-239.

54. Candolfi E., et al. "Detection of circulating antigen in trichinellosis by immuno-enzymology. Comparative results in mice, rats and humans". In: Trichinellosis, Proceedings of the Seventh International Conference on Trichinellosis (1989): 194-201.

55. Li CKF., et al. "The distribution of excretory/ secretory antigens during the muscle phase of Trichinella spiralis and T. psuedospiralis infections". Parasitology Research 85.12 (1999): 993-998.

56. Pajersky A., et al. "Susceptibility and reaction of sheep to Trichinella pseudospiralis infection". Helminthologia 33.2 (1996): 67-71.

Volume 1 Issue 2 February 2018

(C) All rights are reserved by Dalia S Ashour., et al. 